\title{
DESENVOLVIMENTO E POLÍTICAS SOCIAIS FOCALIZADAS: DA CONCEPÇÃO DE ESTADO À CONCEPÇÃO DE MERCADO
}

F. R. B. GOMES DA SILVA ', A. J. LIMA

Universidade Federal do Piauí

robertbandeira@hotmail.com ${ }^{*}$

Submetido 30/08/2016 - Aceito 07/02/2017

DOI: $10.15628 /$ holos.2017.5040

\section{RESUMO}

O objeto de investigação do presente texto é a política social focalizada, em particular, busca demonstrar que as políticas sociais focalizadas não são apenas de cunho residual, podem ser ainda aliadas à políticas universalizantes, o que as tornam redistributiva. Tal objetivo se faz salutar no momento em que as políticas sociais focalizadas são crucificadas como apenas residuais.

PALAVRAS-CHAVE: Política Social, Residual, Redistributiva.

\section{DEVELOPMENT AND SOCIAL POLICIES FOCUSED: MARKET DESIGN TO THE DESIGN STATE}

\section{ABSTRACT}

The research object of this text is focused social policy, in particular, seeks to demonstrate that targeted social policies are not only residual imprint can still be allied to universalizing policies, which make redistributive. This objective becomes healthy at the time that the targeted social policies are crucified as just waste.

KEYWORDS: Social Policy, Residual, Redistributive. 


\section{INTRODUÇÃO:}

O desenvolvimento é lugar-comum nos debates econômicos, em particular, com o neoliberalismo, que se tornou alternativa às burocracias governamentais estranguladoras do espírito empreendedor e dos interesses individuais. A existência do Estado não era um problema, mas como ele atua no processo de desenvolvimento, isto é, o tamanho da sua área de abrangência - grande ou mínima. Os defensores do desenvolvimento que privilegiam o mercado como instituição desejam um Estado mínimo, que atue na proteção das pessoas, dos seus direitos e da propriedade privada. Por outro lado, os partidários da atuação maciça do Estado rejeitam o mercado como um lócus social válido na medida em que enxergam nas trocas livres um patamar nocivo ao cidadão, a exemplo do desemprego e sucateamento dos direitos de cidadania (a saúde, a educação, a habitação e o saneamento), que gera uma exclusão social.

Nessa dicotomia do tamanho do Estado residem diversos temas, em particular, a concepção das políticas públicas ora focalizadas, ora universais, que a priori se alistariam na concepção de mercado e de Estado respectivamente. Porém, o presente artigo pretende verificar se as políticas focalizadas podem ser interpretadas através do arcabouço das políticas de concepção de Estado, isto é, redistributivas e não apenas como residuais.

O objeto de investigação do presente texto é a política pública focalizada. Grande parte da literatura denota que a política pública focalizada é residual e tem como gênese as políticas neoliberais. Tais políticas privilegiam em sua essência o mercado e a diminuição do alcance do Estado nas relações privadas. O espaço que as políticas sociais têm no sistema neoliberal é muito pequeno, destina-se apenas aos muito pobres - os excluídos, aqueles que não conseguem viver no e do mercado. Assim, a noção que se tem das políticas sociais focalizadas é que elas são direcionadas aos "incapazes" do sistema de mercado o que reforça o estigma social.

As políticas neoliberais são frutos de reformas estatais em decorrência da crise do Estado de Bem-Estar Social, na Europa, e do Estado Desenvolvimentista, na América Latina, por exemplo. A maior atuação do Estado se fez, em particular, logo após a Segunda Guerra Mundial que proporcionou aos Welfare States a expansão e consolidação de sistemas de proteção social. Com isso, as relações sociais, em particular, as privadas eram reguladas pelo Estado em que a proteção social deixa de ser emergencial para se institucionalizar via direitos de cidadania (Marshall, 1967). 
Na década de 1970 o Estado passa por alterações, principalmente, no que diz respeito á sua intervenção na esfera privada. De acordo com os neoliberais as modificações se deram no mercado com a disseminação da sua autonomia frente ao Estado e na alteração de suas leis constitucionais. No que concerne às modificações constitucionais pode-se confirmar que o Estado altera significativamente o padrão de regulação do trabalho, com a flexibilização das relações de trabalho, no que se refere às formas de contratação, determinação da remuneração, jornada de trabalho, solução dos conflitos, por exemplo. Assim, as políticas se voltam ao fortalecimento do mercado e à diminuição da abrangência do estado, porém isso não significa um Estado fraco, tanto que o Estado modifica as leis constitucionais para que o mercado atue o mais livre possível.

Um dos resultados da atuação neoliberal nos Estados é a constante privatização das empresas estatais, a exemplo da Vale do Rio Doce e as empresas de telefonia no Brasil. Suas políticas identificam que o emprego público onera a poupança estatal, por isso sugere as privatizações, a crise da Grécia no ano de 2013 corrobora tal afirmação. Dessa forma, os neoliberais elegem o mercado como o local de excelência em que a prestação de serviços está imune dos atos de corrupção dos Estados em que têm grande atuação na esfera privada.

É a partir desse padrão neoliberal de política de autonomia do mercado que surgem as políticas públicas focalizadas de cunho residual. São residuais por conta de eleger como beneficiários os que não participam do mercado de trabalho via seguros e transferências de renda. Com isso, a política social é de fato uma política econômica.

Mas a política social focalizada pode ser interpretada somente pelo viés residual? A hipótese que guia o presente texto é que o espírito da política social focalizada depende do tipo de justiça que a guia, a de estado ou a de mercado. A justiça de Estado não menospreza o âmbito econômico, porém intervém na esfera privada com o intuito de aliviar as desigualdades sociais. A justiça de mercado delega à economia os benefícios sociais, ao atuar residualmente no que concerne às políticas sociais (Kerstenetzky, 2006). Outro pressuposto é que as políticas sociais focalizadas podem ter um caráter redistributivo desde que seja parte de programas universais, prática mais característica da socialdemocracia dos países da Escandinávia (Kerstenetzky, 2006).

A presente análise se restringe ao âmbito teórico da discussão e tem como pressuposto que a política focalizada pode ser interpretada tanto no seu viés residual, quanto na perspectiva redistributiva (Kerstenetzky, 2006). Assim, estrutura-se na vertente qualitativa da pesquisa, em particular, na utilização do método da revisão bibliográfica através dos temas a seguir que ainda 
servem de divisão do artigo: a) política social focalizada de cunho residual (KERSTENETZKY, 2006; MARSHALL, 1967; SMITH, 1983; MORAES, 2001); b) as políticas focalizadas em um contexto de bem-estar social (Kerstenetzky, 2006; Esping-Andersen, 1991; Offe \& Lenhardt, 1984; Kerstenetzky, 2009).

\section{REVISÃO BIBLIOGRÁFICA:}

\subsection{Política social focalizada de cunho residual}

A ideia central dessa seção é a noção de política social focalizada. Aqui a ênfase é ao paradigma da focalização em que a justiça é a de mercado. Essa noção é orientada pelo espírito liberal, em que o mercado é o provedor dos bens sociais e a parcela que cabe ao Estado é a de garantir a segurança interna e a externa, assim como a de assegurar a propriedade e os contratos.

Traduz-se em um enfoque que prega uma mínima intervenção do Estado nas relações econômicas, ou seja, limita rigorosamente o espaço público e o privado, sem que os mesmos criem uma intersecção. Tal modelo se faz contra o domínio do público no âmbito privado dos indivíduos. Isso decorre da ineficiência da intervenção pública, que segundo essa vertente produz privilégios e desigualdades intransponíveis por conta do prestígio social que é dado a uns e a outros não.

A classe que impulsiona tal ideia se protege com o discurso da institucionalização dos direitos, em particular, o de liberdade econômica, política e social. Defende uma posição em que os direitos de liberdade se constituem um componente resiliente no âmbito do mercado. Porém, a provisão social via mercado é incerta, uma vez que o sistema mercadológico não tem como assegurar um alívio da desigualdade social, já que a priori o sistema em tela preocupa-se com a lucratividade.

Neste contexto, as políticas sociais defendidas sob o prisma do mercado são as targeted policies. Políticas sociais focalizadas, em que o objetivo primordial é atender os excluídos dos processos econômicos. "A focalização aparece, portanto, como um componente (menor) da racionalidade do sistema, de sua eficiência global. A verdadeira 'política social' seria, na verdade, a política econômica" (Kerstenetzky, 2006, p. 568). Destaca-se que o lugar que a perspectiva de mercado reserva à política social é a simples provisão de um seguro contra os inconvenientes da vida. 


\subsubsection{O legado do liberalismo clássico nas políticas sociais focalizadas}

As políticas sociais focalizadas de cunho residual podem ser observadas, dentre outras perspectivas sob a institucionalização dos direitos sociais que pregava T. H. Marshall $(1967$, p. 62) "a desigualdade do sistema de classes sociais pode ser aceitável desde que a igualdade de cidadania seja reconhecida". As desigualdades materiais provenientes do mercado são aceitáveis, mas todos são iguais perante a lei, isto é, o autor reconhece uma igualdade instrumental racional e não material. Porém, essas desigualdades provenientes do mercado podem ser suprimidas pelo Estado via institucionalização dos direitos sociais, na execução de políticas sociais, que a princípio são residuais.

A Poor Law é uma aproximação das políticas sociais focalizadas de cunho residual. A ideia central do corpo de leis que englobam a Poor Law é proporcionar um alívio para os mais pobres. "A Poor Law elisabethiana era, afinal de contas, um item num amplo programa de planejamento econômico cujo objetivo geral não era instalar uma nova ordem social, e sim preservar a existente com o mínimo de mudança essencial" (Marshall, 1967, p. 71). Em outras palavras, tinha a função de contribuir com o progresso econômico ao mesmo tempo em que amparava os realmente pobres, isto é, os que se encontravam marginais ao sistema de mercado.

Pela Lei de 1834 a Poor Law renunciou a todas as suas reivindicações de invadir o terreno do sistema salarial ou de interferir na força do mercado livre. Oferecia assistência somente aqueles, que devido à idade e à doença, eram incapazes de continuar a luta e àqueles outros fracos que desistiam da luta admitiam a derrota e clamavam por misericórdia (Marshall, 1967, p. 71).

Através dessa passagem Marshall (1967) quer demonstrar o divórcio entre os direitos civis, políticos e sociais. Segundo o autor, os beneficiários da Poor Law estavam renunciando dos seus direitos de cidadania, uma vez que o Estado os encaminhava as casas de trabalho (perdendo o seu direito civil e político), por exemplo. Tal afirmação se dá em decorrência da cidadania de Marshall (1967) ser decorrente da junção dos três direitos ora mencionados.

Por outro lado, a citação extraída da obra "Cidadania, Classe Social e Status" vem a corroborar a natureza residual da focalização de uma política social. Deixava o mercado livre, porém viria interferir somente quando os indivíduos viessem a atingir uma idade avançada, quando esses estivessem acometidos de doenças e, por fim, amparar aqueles que eram indigentes. Pode-se perceber que a política se fazia em uma espécie de previdência social, porém bastante focalizada e residual. 
A mesma natureza política se fazia nos Factory Acts. Atos responsáveis por melhorias nas condições de trabalho e da redução de horas diárias de trabalho (Marshall, 1967). Porém focalizava-se somente nas mulheres e nas crianças, o homem adulto não fazia parte dessa política social. A não inclusão do homem adulto nos Factory Acts encontrava morada no discurso progressista da época, qual seja: "por respeito a seu status como cidadão com base na alegação de que medidas protetivas coercivas afrontavam o direito civil de efetuar um contrato de trabalho livre" (Marshall, 1967, p. 73).

Outra vez o que prevalece é a noção mercadológica da política. Na Poor Law os indivíduos que eram por ela assistidos não eram mais objeto de interesse do mercado, estavam alijados do processo, mas deviam ser assistidos pelo Estado para que não "manchassem" o sistema. No Factory Acts a não participação dos homens adultos como beneficiários se justifica na função primordial do liberalismo, a garantia de contratos que J. Locke já dizia ser o Estado responsável por sua garantia na forma de propriedade privada e mais tarde corroborada por Adam Smith em sua tripla função do Estado. Isso de acordo com Moraes (2001, p. 13) prega:

[...] a necessidade de desregulamentar e privatizar as atividades econômicas, reduzindo o Estado a funções definidas, que delimitassem apenas parâmetros bastante gerais para as atividades livres dos agentes econômicos. São três as funções do governo na argumentação de Smith: a manutenção da segurança interna e externa, a garantia da propriedade e dos contratos e a responsabilidade por serviços essenciais de utilidade pública.

Para kerstenetzky $(2006$, p. 568) a política social na perspectiva de mercado "[...] envolve uma certa visão moral sobre o que deve e o que não deve ser objeto de responsabilidade pública". O exemplo dos que são e que não são beneficiários da Poor Law e dos Factory Acts. Corrobora com a noção de política social como uma simples provisão de um seguro contra os inconvenientes da vida, que é sempre construído a partir de interesses diferenciados e de relações de forças, isto é, de um paradigma.

Ainda na não inclusão do homem adulto nos Factory Acts sob o motivo da não intervenção estatal nos contratos celebrados livremente pode-se realizar algumas interpretações adicionais. Em primeiro momento não considera as mulheres cidadãs ao aceitar o divórcio entre os direitos sociais e os civis, isso na perspectiva de Marshall (1967). Nesse raciocínio, caso as mulheres reivindicassem o seu direito de cidadania sob a perspectiva de Marshall (1967) deveriam perder a proteção contida nos Atos. 
Em outra análise, reforça o princípio do mercado que assevera que o ele é o melhor caminho para gerar eficiência. Nas palavras de Adam Smith (1983, p. 47):

[...] uma vez eliminados inteiramente todos os sistemas, sejam eles preferenciais ou de restrições, impõe-se por si mesmo o sistema óbvio e simples da liberdade natural. Deixase a cada qual, enquanto não violar as leis da justiça, perfeita liberdade de ir em busca de seu próprio interesse, a seu próprio modo, e fazer com que tanto seu trabalho como seu capital concorram com os de qualquer outra pessoa ou categoria de pessoas.

O pensamento de Smith (1983) robustece a noção de direito civil contida nos Factory Acts. Os Atos não atingem o homem adulto para que as leis não criem restrições sob a sua liberdade e o deixe livre para ir à busca de seus interesses privados. Os Atos interferem apenas nas mulheres e crianças, de forma residual ao considera-los uma parte fraca do sistema de mercado, parcela social que sofre, na concepção liberal, os inconvenientes da vida.

A justiça de mercado no que diz respeito às políticas sociais teve um intervalo que compreende a década de 1930 a 1970, momento do predomínio de políticas em que o Estado aumenta a sua intervenção na esfera privada do indivíduo, isto é, cria um desvirtuamento das ideias residuais, carro-chefe dos liberais. Essa é a época áurea do Estado de Bem-Estar Social na Europa e do Estado Desenvolvimentista na América Latina.

Os Estados de Bem-Estar Social e Desenvolvimentistas têm em sua gênese a participação do governo nos assuntos privados, como a previdência, a educação e a saúde, por exemplo. Comportam tanto a política social universal (os países escandinavos são exemplos de excelência), como a focalizada, seja ela residual (E.U.A., Canadá e Austrália) ou conservadora (França, Alemanha e Itália, na Europa e Brasil, Argentina, na América Latina, são alguns exemplos).

A década de 1930 é o início de reformas do Estado ocasionada, em parte, pela falência do sistema liberal com a quebra da Bolsa de Nova lorque em 1929. Já a década de 1970 configura a crise dos modelos de bem-estar social e desenvolvimentista. Década que assistiu o endividamento dos Estados, onde a equação keynesiana, por exemplo, não mais se sustentara, isto é, as despesas estatais a muito eram superadas pelas receitas, principalmente, nas contas da previdência. Sem deixar de mencionar que o mercado global entra em crise, em particular, com o aumento vertiginoso dos preços do Petróleo, combustível por excelência da economia mundial até os dias atuais.

Como resposta à crise do Estado de Bem-Estar Social, entraram em prática as políticas neoliberais. É o conhecido ajuste estrutural que vai de encontro às teorias e práticas de um 
Estado que intervém na economia e na esfera privada do indivíduo. Não se trata de um novo liberalismo, mas um liberalismo em uma nova época. O problema não é mais o Estado Absolutista, mas o Estado de Bem-Estar Social, os Estados Ditatoriais, Socialistas e todo aquele que planificava a sua economia. Apesar da nova época os inimigos, como assevera Moraes (2001), revelavam as mesmas taras e perversões.

\subsection{As políticas focalizadas em um contexto de bem-estar social}

O liberalismo por si só não consegue sustento, em particular, após a II Guerra Mundial. O Paradigma vigente não era exclusivamente liberal, surge um Estado que visa reconstruir a Europa e diminuir as desigualdades mundo ao redor do mundo: O Estado de Bem-Estar Social. Nessa seção o intuito é conceituar o Estado de Bem-Estar Social e analisar se as políticas sociais focalizadas continuam exclusivamente com o seu caráter residual.

O Estado de Bem-Estar Social tem sido avaliado em diversas perspectivas. Dentre a variedade analítica, observa-se aquela que julga o Welfare State como um aliado do capital. Tal perspectiva coloca as políticas sociais no patamar de auxílio ao avanço do capitalismo. Há ainda a que trata de avaliar o caráter funcional do conteúdo estatal ou de áreas específicas da atividade do Estado. Traduz-se, assim, em uma observância da relação funcional entre a atividade estatal e os problemas estruturais da formação social capitalista. Em um terceiro momento, constata-se a presença de estudos que critica a funcionalidade das políticas públicas ao imprimir um caráter institucional, o de garantir direitos, em particular, os sociais.

A compreensão da política social e pública não cessa nas orientações procedimentais e funcionais do Estado. É importante considerar a formação histórica de cada país para realizar um entendimento sobre cada formato de política. Existe, antes de tudo, a análise ideológica do surgimento da política social e pública, que se faz diferente em vários contextos de alianças partidárias, de modo de produzir as decisões, assim como o espírito da sua economia política.

A conceituação do Estado de Bem-Estar Social refere-se, em particular, ao modelo que se concretizou anterior á sua crise que eclodiu na década de 1970 e se fez sentir até a década de 1990. Seus conceitos oscilam entre a forte e a pacata presença do Estado via seguros e políticas sociais.

Antes de qualquer especificação teórica acerca do Estado de Bem-Estar Social existem três princípios a serem levados em consideração, são eles: o Estado, a família e o mercado. A compreensão sobre o Estado de Bem-Estar Social passa pelas formas como as atividades estatais 
se relacionam com a família e o mercado no que se refere às providências sociais (EspingAndersen, 1991).

As compreensões teóricas sobre o Estado de Bem-Estar Social passam ainda pelo crivo analítico do que se refere aos graus de mercadorização e a desmercadorização. Mercadorização é "quando os mercados se tornaram universais e hegemônicos é que o bem-estar dos indivíduos passou a depender inteiramente de relações monetárias" (Esping-Andersen, 1991, p. 102). Já a desmercadorização "ocorre quando a prestação de um serviço é vista como uma questão de direito ou quando uma pessoa pode manter-se sem depender do mercado" (Esping-Andersen, 1991, p. 102). Na dicotomia mercadorização e desmercadorização têm-se os seguintes exemplos: o primeiro, de mercadorização é um exemplo de previdência social em que Draibe $(2003$, p. 91) refere-se:

[...] à introdução do princípio de contribuição definida, segundo a expectativa do ganho futuro, substituindo o princípio de benefício definido". Em via de regra, sem mencionar as exceções, recebe uma pensão ou aposentadoria aquele que contribui e proporcionalmente à contribuição, o que caracteriza como um política social focalizada. O outro exemplo, o de desmercadorização é o sistema público universal de saúde da suécia, para acessar tais direitos não é necessário estar ligado ao mercado de trabalho.

O mercado ficou instituído como um veículo privado de satisfação social que as pessoas se agarravam. Por outro lado um fator associado era a presença da desigualdade social existente, um fosso social entre os capitalistas e os seus operários. É a partir de tal desigualdade social, que se constata que uma parcela da sociedade dependia da venda da sua força de trabalho para garantir a sua sobrevivência. São para essas pessoas que as primeiras iniciativas do Estado de Bem-Estar Social foram criadas, em particular, para reinseri-las no mercado e criar condições para que elas se mantenham empregadas.

O ponto de partida da discussão aqui traçado é a tese defendida por Claus Offe e Gero Lenhardt (1984), em que as políticas de Estado, em particular, denominadas de social se fizeram para inserir pessoas economicamente ativas no mercado de trabalho. Em outras palavras, o Estado assumia a responsabilidade por reinserir a força de trabalho no mercado - transformar os despossuídos em assalariados.

O intuito supremo da política social estatal é regulamentar o processo de proletarização, transformar a proletarização passiva em ativa. "A transformação da força de trabalho despossuída em trabalho assalariado é, ela mesma, parte do processo constitutivo da política 
social, cuja efetivação não pode ser somente explicada pela 'coerção muda das relações econômicas'" (Offe \& Lenhardt, 1984, p. 20).

\begin{abstract}
Se o problema da proletarização, da inserção da força de trabalho no mercado de trabalho não pode se resolver "por si só" em um sentido que possa ser levado a sério do ponto de vista das ciências sociais, devemos perguntar que estruturas parciais da sociedade teriam agido funcionalmente com vistas à solução desse problema estrutural. Defendemos aqui a tese de que a transformação em massa da força de trabalho despossuída em trabalho assalariado não teria sido, nem é possível sem uma política estatal (Offe \& Lenhardt, 1984, p. 16-17).
\end{abstract}

Nessa perspectiva Offe e Lenhardt (1984) fazem uma leitura de que os seguros sociais, a educação profissional e o atendimento de saúde, todos ofertados pela iniciativa estatal são políticas sociais que visam reinserir o trabalhador no mercado de trabalho ao fazer com que a classe trabalhadora possua um sustentáculo púbico. Tais políticas beneficiam, ainda, o Estado no momento em que ele evita problemas sociais causados pelo longo tempo de desemprego, por exemplo. Em outras palavras são políticas sociais mercadorizantes.

A política social demonstrada na perspectiva de Offe e Lenhardt (1984) denota uma política focalizada, porém não se encaixa no modelo residual. Na perspectiva dos autores a reinserção do operário no mercado não se traduz em um raciocínio mercadológico puro. O Estado não necessariamente está buscando atingir os mais pobres como prega o residualismo. A preocupação reside em uma mão dupla: tanto no mercado, quanto no Estado.

De acordo com Esping-Andersen (1991) a institucionalização dos direitos geram impactos diferenciados, os seus resultados dependem diretamente das especificidades estatais, ou como os Estados se relacionam com o mercado. Existem três modelos baseados na desmercadorização, são eles: a) os baseados em benefícios reduzidos que servem para limitar os efeitos de desmercadorização; b) aqueles em que os benefícios dependem quase inteiramente de contribuições, assim como de trabalho e emprego, e o mais desmercadorizante de todos; c) em que oferta benefícios básicos e iguais para todos, políticas essas que independem de ganhos, contribuições e de qualquer participação anterior no mercado.

Para cada um desses modelos Esping-Andersen (1991) tipificou como regimes, quais sejam: 1) Liberal; 2) Conservador, e; 3) Socialdemocrata. O regime liberal direciona-se aos comprovadamente pobres o que provoca um estigma social. Os benefícios sociais, em sua maioria, tem um alcance muito limitado. Atinge, em particular, os trabalhadores e os 
dependentes do Estado. Esse regime favorece o mercado no momento em que garante o mínimo social a classes mais pobres da população e por subsidiar esquemas privados de previdência.

O regime Conservador caracteriza-se por uma presença maior do Estado se comparado com o regime Liberal, pois o Estado era o gestor do capitalismo. É conhecido por um forte corporativismo, que se faz perceber ao observar que os direitos se ligavam à classe e ao status. Tal ligação, em particular, a de status se faz perceber por não haver um impacto de redistribuição, pelo contrário, mantinha as desigualdades entre as classes. O cunho corporativista se faz notório por conta do reconhecimento de certos direitos, como o trabalhista, apenas para poucas profissões (Esping-Andersen, 1991).

O último regime, o Socialdemocrata, tem a igualdade e a universalização dos direitos sociais como essência. Direitos que são desfrutados por classes mais altas são os mesmos que os das classes mais baixas, o que provoca igualdade e desconsidera o corporativismo predominante do modelo conservador. Tem como guia o pleno emprego, faz com que o cidadão escolha entre ficar empregado ou receber um auxílio social, o caso das mulheres é bem emblemático. O regime em tela é considerado o mais desmercadorizante de todos (Esping-Andersen, 1991).

É, portanto, que a escolha de uma política social universal se faz mais satisfatória do que uma focalizada, pois não vem apenas aliviar a pobreza ou se curva a pressões classistas, mas faz com que o indivíduo opte a sair do mercado no momento em que desejar, como visto no modelo socialdemocrata dos países da Escandinávia. Com isso, a saída para os Estados mais desiguais seria a universalização dos direitos sociais e abandonar a focalização? A resposta a essa questão é o objetivo da próxima seção.

\section{CONCLUSÃO:}

De início deve-se questionar a gênese da universalização e da focalização das políticas sociais. Kerstenetzky (2006) preceitua que tanto as políticas sociais universais, quanto as focalizadas podem responder a dois tipos de justiça, quais sejam: a de mercado e a de Estado, já mencionadas no presente texto. Assim, a autora afirma que existem políticas universais baseada nas justiças sociais de mercado e de Estado.

Os tipos-ideais seriam: a) Focalização e universalização residual, baseada na concepção de justiça de mercado, e; b) Focalização e universalização baseada na concepção de justiça de Estado. A focalização de acordo com a justiça mercadológica é "[...] uma rede de proteção social 
mínima" (Kerstenetzky, 2006, p. 572), a exemplo dos modelos liberais de Estado de Bem-Estar Social classificado por Esping-Andersen. A universalização da concepção de mercado garante educação, a saúde e a previdência social, todas de caráter básico. "A diferença entre focalização e universalização, no âmbito de uma concepção de justiça de mercado, estaria principalmente no tamanho do resíduo" (Kerstenetzky, 2006, p. 572).

Já a diferença que existe entre as políticas sociais focalizadas e universais perante uma concepção de justiça de Estado é: a) Políticas universais: "seguridade social, educação e saúde universais e generosas - como parece ser a experiência escandinava" (Kerstenetzky, 2006, p. 572); b) Políticas focalizadas: "alocação redistributiva de recursos de geração de oportunidades sociais e econômicas para os grupos sociais em desvantagem relativa" (Kerstenetzky, 2006, p. 572).

No Brasil desde o governo de Fernando Henrique Cardoso as políticas sociais vieram casadas, focalizadas com universais, com exceção das políticas de previdência social e de trabalho. Para Draibe (2003, p. 90), “A focalização no interior dos programas universais foi a orientação observada, no período, com vistas a melhorar seu impacto redistributivo"

É importante destacar que a ideia não é avaliar se a estratégia deu certo ou não, mas a de demonstrar que existem políticas sociais focalizadas redistributivas. Outro exemplo, ainda no Brasil é o do Programa Bolsa Família, das cotas de ingresso às universidades, a isenção de taxas de inscrição nos concursos públicos, Programa Minha Casa Minha Vida. São programas focalizados, mas que visam redistribuir os bens sociais, em particular, aos mais necessitados ou para aqueles que não os possuem.

De acordo com Kerstenetzky (2009), O Brasil apresenta uma pequena queda no nível da desigualdade. Tal queda se deve a duas razões, a primeira é a expansão do mercado formal de trabalho com os constantes reajustes do salário mínimo. A segunda razão são os programas sociais, em particular, o Programa Bolsa Família - PBF. Destaca-se que as políticas focalizadas redistributivas não ignoram o mercado, porém, não o fazem dele o seu guia central.

Um exemplo prático da política focalizada redistributiva são os resultados do PBF. No ano de 2004 a queda de desigualdade foi de $21 \%$, isso se deve à complementação de renda a um número substancial de pessoas que se encontram na base da pirâmide social. Um fato que corrobora essa afirmação é que as transferências de renda contribuíram para combater a subnutrição infantil, de acordo com Kerstenetzky (2009, p. 58), "de fato, estima-se que 87\% das transferências foram utilizadas pelas famílias para comprar alimentos". 
Apesar do grande sucesso do PBF existem ainda muitas críticas. Uma delas é constatada na falta de apoio da classe média no episódio do fim da CPMF. As transferências de renda do PBF ficam estigmatizadas no momento em que apenas uma parcela muito pobre recebe o benefício, uma solução apontada por Kerstenetzky (2009) é a abrangência do programa também para classe média. Outra crítica se faz no vazamento, que é entendido como um processo em que não somente os muito pobres são atendidos, mas algumas pessoas que não se encaixariam como beneficiários ao mesmo tempo que deixa de fora muitos de seus reais beneficiários.

O intento aqui não é avaliar o PBF, mas demonstrar que ele configura, pelo menos em sua essência, uma política focalizada redistributiva, que pode ser aliada a condicionantes nas áreas da educação e da saúde básica. Pode-se inferir que o desenho do PBF se faz como um contributo para o desenvolvimento do Brasil.

\section{REFERÊNCIAS}

Draibe, S. M. (2003). A política social no período FHC e o sistema de proteção social. Tempo Social, p. 63-101.

Esping-Andersen, G. (1991). As Três Economias do Welfare State. Lua Nova, n. 24, p. 85-116.

Kerstenetzky, C. L. (2012). O Estado do Bem-Estar Social na Idade da Razão: a reivenção do estado social no mundo contemporâneo. Rio de Janeiro: Elsevier.

Kerstenetzky, C. L. (2009). Redistribuição e Desenvolvimento? A Economia Política do Programa Bolsa Família. Dados, v. 52, n. 1, p. 53-83.

Kerstenetzky, C. L. (2006). Políticas Sociais: focalização ou universalização? Revista de Economia Política, v. 26, n. 4, p. 564-574.

Marshall, T. H. (1967). Cidadania, Classe Social e Status. Rio de Janeiro: Zahar.

Moraes, R. (2001). Neoliberalismo: de onde vem, para onde vai? São Paulo: Editora Senac.

Offe, C. \& Lenhardt, G. Teoria do Estado e Política Social: tentativas de explicação políticosociológica para as funções e os processos inovadores da política social. In. Offe, C. (1984). Problemas Estruturais do Estado Capitalista. Rio de Janeiro: Tempo Brasileiro.

Smith, A. (1983). A Riqueza das Nações: investigação sobre sua natureza e suas coisas. Vol. 2. São Paulo: Abril Cultural. 